\title{
Recurrent Infections and Rash in a 6 Year Old Girl: A Case Report of Congenital $\mathrm{C}_{3}$ Defeciency
}

\author{
ZH DARAZ $^{\mathrm{a}}$, MI ISLAM ${ }^{\mathrm{b}}$, SARAHMAN $^{\mathrm{c}}$
}

\begin{abstract}
Summary:
Primary complement deficiencies are very rare and a case of 6 year old girl with complement 3 deficiency is reported here who presented with recurrent infections and rash since her early childhood. She had several episodes of respiratory tract infections, urinary tract infections and various episodes of gastro enteritis and was treated subsequently every time with injectable antibiotics. Later she developed encysted hydropneumothorax with mild pleural thickening with compression collapse of adjacent right lung. On investigation
\end{abstract}

\section{Introduction:}

Primary immunodeficiency diseases (PID) are a group of rare, chronic disorders in which part of the body's immune system is missing or functions improperly. While not contagious, these diseases are caused by hereditary or genetic defects. ${ }^{1}$ Some disorders present at birth or in early childhood, and the disorder can affect anyone, regardless of age or gender. Some affect a single part of the immune system; others may affect one or more components of the system. ${ }^{2}$

Body's immune system has efficient complement system which is duly concerned with innate immunity. It is formed of various proteins that are activated by different triggering factors which proceed to a chain of events in the human body finally forming a cytolytic "membrane attack complex" that plays a crucial role in fighting the infection. $^{3}$

Complement component $3\left(\mathrm{C}_{3}\right)$, is a protein that plays a central role in the complement system and

1. Dr. Zahoor Hussain Daraz, Bangabandhu Sheikh Mujib Medical University (BSMMU), Dhaka

2. Dr. Mohammad Imnul Islam, Associate Professor, Department of Paediatrics

Bangabandhu Sheikh Mujib Medical University (BSMMU)

3. Prof. Shahana Akhtar Rahman, Professor of Department of General Paediatrics and Pro Vice Chancellor of Bangabandhu Sheikh Mujib Medical University (BSMMU)

Address of Correspondence: Dr. Mohammad Imnul Islam, Associate Professor, Department of Paediatrics, Bangabandhu Sheikh Mujib Medical University (BSMMU), Email: imon27@gmail.com, Mob: +8801711393049

Received: 4 March 2019

Accepted: 15 Jan. 2020 complement 3 level was found below normal both in the patient and in her parents and younger sister. This case is reporting here in order to disseminate the message that underlying cause of recurrent infections could be primary immunodeficiency $\left(C_{3}\right)$.

Key words: Compliment $3\left(C_{3}\right)$, Primary Immune deficiency (PID), Membrane Attack Complex (MAC)

(J Bangladesh Coll Phys Surg 2020; 38: 101-104)

DOI: https://doi.org/10.3329/jbcps.v38i2.45636

contributes to innate immunity. It is the major and central event in activation of complement system that is triggered by proteolysis of $\mathrm{C}_{3}$, which produces $\mathrm{C}_{3} \mathrm{~b}$ and $\mathrm{C}_{3} \mathrm{a} \cdot \mathrm{C}_{3} \mathrm{~b}$ is covalently bound to the cell surface or antigen-antibody complex that triggers the later steps of complement activation which is common to all 3 pathways, the process leads to the formation of lipidsoluble pore structures of the membrane attack complex( MAC). ${ }^{4}$ There are 3 different pathways of complement activation and deficiency of each component of the classical and alternate pathways is rare and comprises less than $1 \%$ of patients with primary immunodeficiency. ${ }^{5}$ However deficiency of components of the Mannose binding lectin pathway appears to be comparatively common. Autoimmune disease can occur due to early component deficiency in classical pathway. Late component deficiency of complements leads to increased susceptibility to certain infections. Each of the three pathways have different triggering stimuli however they all converge at the component $\mathrm{C} 3$, because the common goal is to deposit formed clusters of $\mathrm{C} 3 \mathrm{~b}$ on a target. This deposition leads to the formation of membrane attack complex (MAC), C5b-9. ${ }^{6,7}$ The MAC has a capability of exerting powerful killing activity by creating perforations in cellular membranes. ${ }^{8} \mathrm{~A}$ girl is being reported in this article with hereditary $\mathrm{C}_{3}$ deficiency who presented initially with recurrent respiratory tract (RTI) infections, urinary tract (UTI) infections and later various episodes of gastro enteritis along with urticarial rash of variable size and shape. 


\section{Case Report:}

" $T$ " a 6 year old girl from Gazipur, Dhaka suffered from recurrent infections in the form of pneumonia, UTI, skin abscesses and gastro enteritis since her early childhood. She had skin rash throughout the body for past 2 years along with pain in multiple large and small joints. She was born by LUCS, weighing $3 \mathrm{~kg}$ and had no post natal complications. After her neonatal period she started excessive crying and discharge per ear for which she was treated with oral antibiotics. She did well for a year; thereafter she developed respiratory tract infection diagnosed as pneumonia that was treated with injectable antibiotics (Ceftriaxone) with adequate dose and duration. Till her 4 years of age, she got recurrent attacks of RTI's, UTI's and gastroenteritis. Each time she was treated with broad spectrum antibiotics and other supportive measures. Furthermore an abscess appeared over her right foot which was subsequently drained.

In 2014 ' $\mathrm{T}$ ' at her six year of age presented with rash over her legs that were initially maculopapular in nature however it later turned into petechial, purpuric and somewhat urticarial. (Fig 1) Besides she had arthritis involving multiple large and small joints of both upper and lower limbs including both ankles, both knees and small joints of hands and feet. Joints were swollen, tender and some sorts of limitation were observed at the affected joints. Along with routine investigations skin biopsy was done and report suggested 'Isolated

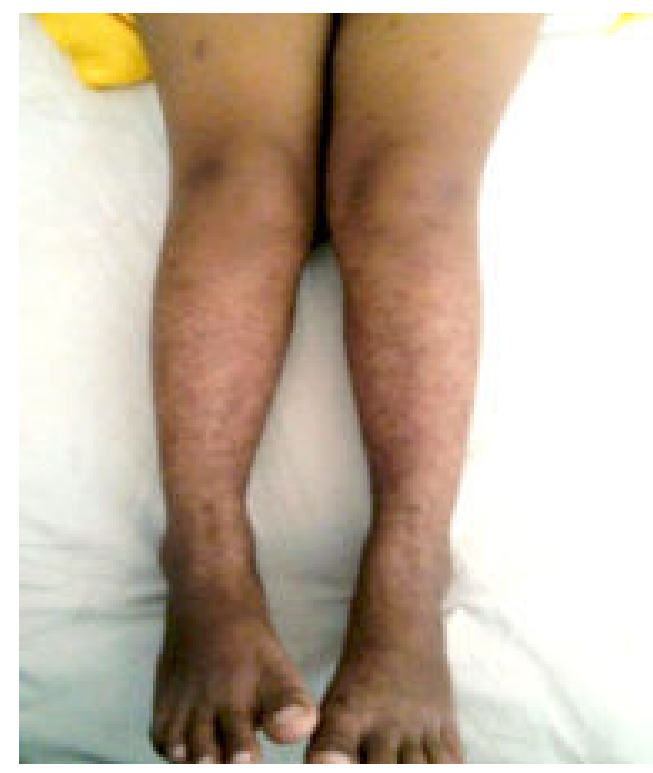

Fig.-1: Showing a diffuse polymorphic rash over Limbs
Leukocytoclastic Vasculitis'. Initially she was diagnosed as a case of Childhood vasculitis most probably HSP and treated with Hydroxyzine, naproxen, emollients and other supportive measures like ranitidine and paracetamol.

T again presented in May 2015 with the complaints of fever and cough along with respiratory distress. Investigations were done including serial CXR's (Fig 2, 3), USG and CT scan of chest (Fig 4) which showed 'Encysted mild Hydro-pneumothorax with mild pleural

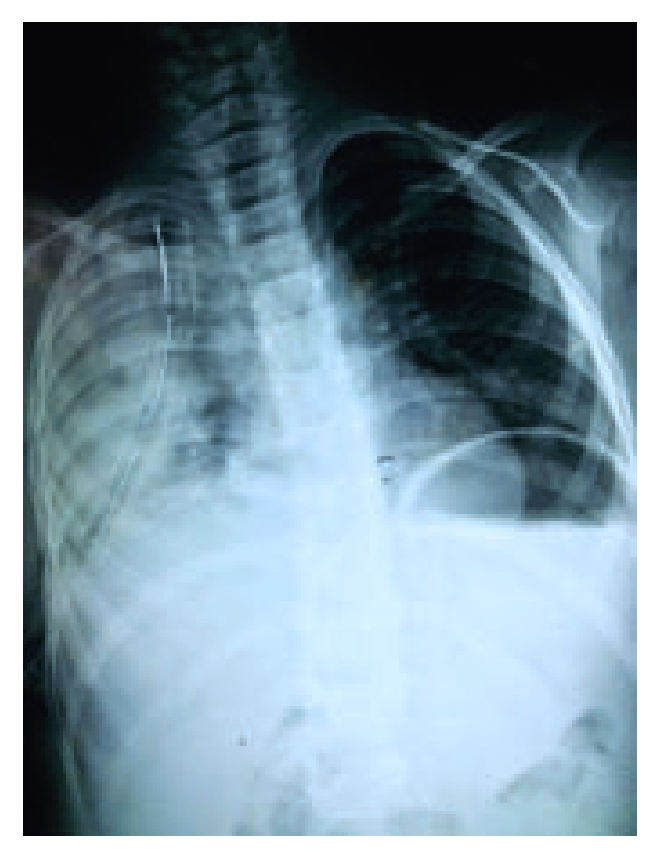

Fig.-2: Xray chest showing drain in situ \& Rt lung opacity

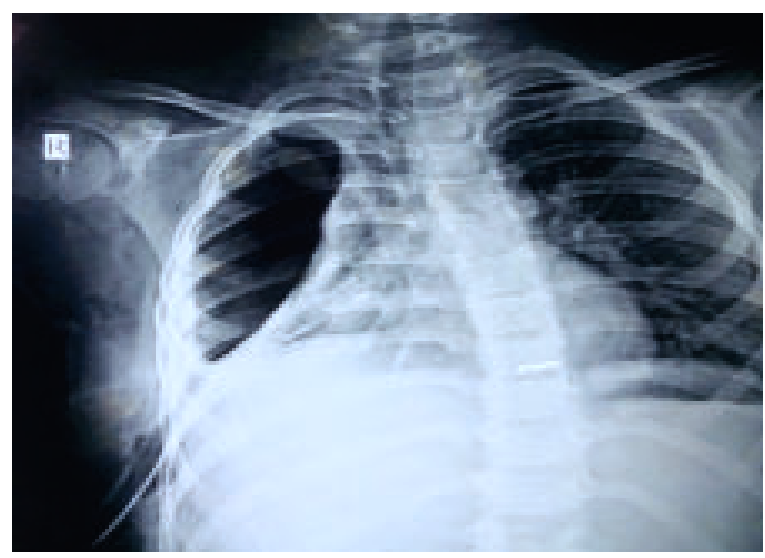

Fig.-3: $X$ ray chest showing compression collapse 


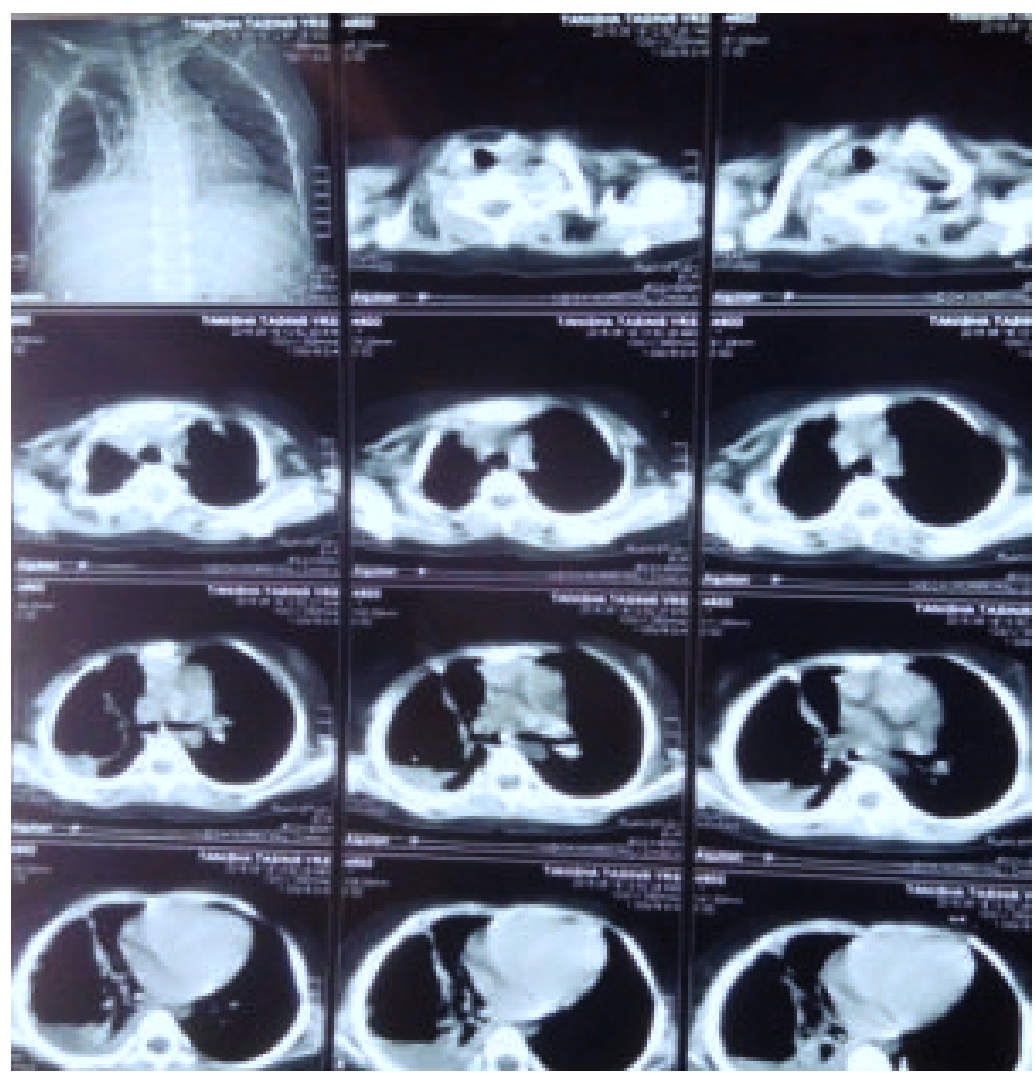

Fig.-4: CT chest showing encysted mild Hydro-pneumothorax with compression collapse of adjacent Right lung

thickening and compression collapse of adjacent right lung'. The chest was subsequently drained and pus culture showed Acinobacter and Enterococcus. Thereafter, right pleurectomy with evacuation of pus with decortication was done. Pus culture showed growth of pseudomonas, sensitive to Amikacin and tube culture showed E-Coli sensitive to Colistin. She was screened along with her family members for immunoglobulin and compliment levels (Parents and younger sister). The reports revealed low levels of $\mathrm{C} 3$ in the index case and all the family members. Her complete blood count revealed mild anemia with mild thrombocytosis and a raised ESR of $70 \mathrm{~mm}$. Her pANCA, cANCA were normal and $\mathrm{CD}^{4} / \mathrm{CD}^{8}$ counts were also normal. Anti dsDNA,ANA titre and. Immunoglobulin levels were within normal limits and $\mathrm{C}_{4}$ level also was normal.

\begin{tabular}{ll}
\hline C3 level of ' $\mathrm{T}$ ' & $<0.184 \mathrm{~g} / \mathrm{L}(0.9-1.8 \mathrm{~g} / \mathrm{L})$ \\
& {$[$ Very Low] } \\
Father's C3 Level & $0.783 \mathrm{mg} / \mathrm{dL}(0.9-1.8 \mathrm{~g} / \mathrm{L})$ Low \\
Mother's C3 Level & $0.706 \mathrm{mg} / \mathrm{dL}(0.9-1.8 \mathrm{~g} / \mathrm{L})$ Low \\
Younger sister's C3 Level & $0.73 \mathrm{mg} / \mathrm{dL}(0.9-1.8)$ Low \\
\hline
\end{tabular}

Besides her treatment, she was vaccinated against Pneumococci, Meningococci, Influenza and Typhoid. Penicillin prophylaxis for prevention of infection ${ }^{8}$ and advised to come on regular follow-up. From history, examination findings and investigations it was observed that the girl $\mathrm{T}$ had hereditary deficiency of Complement $\mathrm{C}_{3}$ which probably the cause of her recurrent infections.

\section{Discussion:}

Primary immunodeficiency diseases (PIDs) are a group of disorders characterized in many ways e.g. defects in antibodies, reduced levels of antibodies or defects in cells and proteins of the immune system which renders a body prone to infections. ${ }^{9}$ In order to consider a primary immunodeficiency, secondary causes due to other diseases, drug or environmental exposure to toxins must be excluded. Primary immunodeficiencies in most of the cases are genetic in origin. Majority of patients are diagnosed in childhood under the age of one, although the milder forms of disease may not be recognized until adulthood. ${ }^{10}$ Currently there is no permanent cure and treatment is palliative consisting of management of infections properly and boosting immune system. ${ }^{11,12}$ 
Dejoie et al reported a case of 5-year old child referred to their hospital with a history of recurrent and prolonged upper respiratory tract infection. Immunologic investigations were normal except complement $\mathrm{C} 3$ which was very low. It was detected by serum protein capillary electrophoresis. Child was treated with Oracillin to control his symptoms. 13

Borzi et al described a 10 years old boy from Loatia who had recurrent pneumonias followed by multiple abscesses over a period of time. After investigation it as was revealed that he has $\mathrm{C} 3$ defiency and his management included antibiotic therapy and plasma infusion as an adjunct boost to immunity. ${ }^{14}$

This reported patient also had recurrent pneumonia, UTI's, skin abscesses and gastro enteritis since her childhood and skin rash over limbs along with pain in multiple large and small joints. In the course of time her condition deteriorated with origin of certain dreadful complications like "Encysted mild Hydro-pneumothorax with mild pleural thickening with compression collapse of adjacent right lung that was subsequently drained with subsequent right pleurectomy and evacuation of pus with decortication.

A similar report by C.A alper et al described a patient with great susceptibility to infection by pyogenic organisms and serum concentration of $\mathrm{C}_{3}$ was found to be very low. Further investigation of her family members (mother and father) revealed $\mathrm{C}_{3}$ levels approximately half of the normal value. ${ }^{15}$

There is no definitive treatment for congenital C3 deficiency. ${ }^{8}$ Counselling the parents about the disease and its course was done properly. Besides that penicillin prophylaxis for prevention of infection and hydroxyzine was prescribed for itchy skin lesion.

\section{Conclusion:}

Hereditary deficiencies of complements although rare but have immense role in infectious origin of diseases and complement $\mathrm{C}_{3}$ is a master molecule in the complement pathway the deficiency of which renders a patient susceptible to infections by all kinds of pathogenic microorganisms. So it is recommended that meticulous investigations in any patient presenting with recurrent and persisting infections needing vigorous antibiotic treatment to exclude PID in general and C3 deficiency in particular.

\section{Conflict of Interest: Non declared.}

\section{References:}

1. Geha RS, Notarangelo LD, Casanova JL, Chapel H, Conley $\mathrm{ME}$, Fischer A et al. International Union of Immunological
Societies Primary Immunodeficiency Diseases Classification Committee: Primary immunodeficiency diseases: an update from the International Union of Immunological Societies Primary Immunodeficiency Diseases Classification Committee. J Allergy Clin Immunol 2007; 120:776-94.

2. Bousfiha A, Picard C, Boisson-Dupuis S, Zhang SY, Bustamante J, Puel A et al. Primary immunodeficiencies of protective immunity to primary infections. Clin Immunol 2010; 135:204-09

3. Bonilla FA, Bernstein IL, Khan DA, Ballas ZK, Chinen J, Frank MM, et al., American Academy of Allergy, Asthma and Immunology, American College of Allergy, Asthma and Immunology, Joint Council of Allergy, Asthma and Immunology: Practice parameter for the diagnosis and management of primary immunodeficiency. Ann Allergy Asthma Immunol 2005, 94:S1-63.

4. Borzy MS, Gewurz A, Wolff L, Houghton D, Lovrien E. Inherited $\mathrm{C} 3$ deficiency with recurrent infections and glomerulonephritis. Am J Dis Child. 1988; 142:79-83.

5. Notarangelo LD, Fischer A, Geha RS, Casanova JL, Chapel $\mathrm{H}$, Conley $\mathrm{ME}$ et al, International Union of Immunological Societies Expert Committee on Primary Immunodeficiencies: Primary immunodeficiencies: 2009 update. J Allergy Clin Immunol 2009; 124:1161-78

6. Manderson AP, Botto M, Walport MJ. The role of complement in the development of systemic lupus erythematosus. Annu Rev Immunol. 2004; 22:431-56

7. Garred P, Pressler T, Madsen HO, Frederiksen B, Svejgaard A, Høiby N,.Et al. Association of mannose-binding lectin gene heterogeneity with severity of lung disease and survival in cystic fibrosis. J Clin Invest. 1999; 104:431-7.

8. Tedesco F. Inherited complement deficiencies and bacterial infections.: Vaccine. 2008, 26 Suppl 8:3-8.

9. Wiertsema SP, Herpers BL, Veenhoven RH, Salimans MM, Ruven HJ, Sanders EA .et al ;Functional polymorphisms in the mannan-binding lectin 2 gene: effect on MBL levels and otitis media. J Allergy Clin Immunol. 2006;117:1344-50

10. Sjoholm AG, Jonsson G, Braconier JH, Sturfelt G, Truedsson L:Complement deficiency and disease: an update. Mol Immunol. 2006; 43:78-85.

11. Fischer A, Hacein-Bey-Abina S, Cavazanna-Calvo M: Gene therapy for primary immunodeficiencies. Immunol Allergy Clin North Am 2010; 30:237-248

12. Walport MJ. Complement. Second of two parts. $N$ Engl J Med. 2001, 344:1140-4.

13. Dejoie T, Audrain M, Bach-Ngohou K, Denis M, LegoueMorillon S, Thomas C, et al. An exceptional component C3 deficiency revealed by serum protein electrophoresis; Ann Biol Clin (Paris). 2009, 67:715-9.

14. Borzy MS, Gewurz A, Wolff L, Houghton D, Lovrien E: Inherited $\mathrm{C} 3$ deficiency with recurrent infections and glomerulonephritis ; Am J Dis Child. 1988; 142:79-83.

15. Alper CA, Colten HR, Rosen FS, Rabson AR, Macnab GM, Gear JS. et al. homozygous deficiency of $\mathrm{C} 3$ in a patient with repeated infections 1972;2: 1179-81. 